\title{
ПСИХОЛОГИЧЕСКИЕ ОСОБЕННОСТИ КАРЬЕРНОГО КОНСУЛЬТИРОВАНИЯ ЖЕНЩИН ПОСЛЕ ДЛИТЕЛЬНОГО ПЕРЕРЫВА В ТРУДОВОЙ ДЕЯТЕЛЬНОСТИ
}

\section{PSYCHOLOGICAL FEATURES OF CAREER COUNSELING FOR WOMEN AFTER A LONG BREAK IN WORK}

N. Bulash

Summary: Relevance. The article explores the psychological characteristics of career counseling for women after a long break in work. The definition of these features in the future can help in the development of secondary adaptation programs for this category of workers. The aim of the study was to conduct a comparative analysis of several diagnostic methods to determine adaptive and motivational factors and to reveal the dependence of these manifestations on the degree of emotional comfort using the example of an experimental group of respondents.

The purpose of the research. Make a comparative analysis of several diagnostic methods to determine adaptive and motivational factors and identify the dependence of these manifestations on the degree of emotional comfort using the example of an experimental group of respondents.

The objectives of the research. The objective of this work was to investigate the main psychological factors affecting the career motivation of this category of women in a job search situation after a long break. This study was conducted among women participating in the Women's History Nonprofit Social Project. In the process of the study, a pattern was found between the imbalance of emotional comfort in one direction or another and the successful process of finding a job, and factors were identified that influence the success of the job search process - psychological and social support.

The results of the research. Identification of the psychological characteristics of career counseling for this category of women, which are aimed at creating differentiated programs for the adaptation of women after a long break in work.

Keywords: career counseling, labor psychology, secondary adaptation, emotional comfort, support for employment.

\author{
Булаш Наталья Викторовна \\ Преподаватель, Финансовый Университет при \\ Правительстве Российской Федерации \\ natalya@bulash.ru
}

Аннотация: Актуальность выбранной темы. В статье исследуются психологические особенности карьерного консультирования женщин после длительного перерыва в трудовой деятельности. Определение данных особенностей в дальнейшем может помочь в разработке программ вторичной адаптации для данной категории работников.

Цель исследования. Сделать сравнительный анализ нескольких диагностических методик для определения адаптационных и мотивационных факторов и выявить зависимость этих проявлений от степени эмоционального комфорта на примере экспериментальной группы респондентов.

Задачи исследования. Задача данной работы было исследовать основные психологические факторы, влияющие на карьерную мотивацию данной категории женщин в ситуации поиска работы после длительного перерыва. Данное исследование проводилось среди женщин, участвующих в Некоммерческом социальном проекте «Женские истории». В процессе исследования выявлена закономерность между дисбалансом эмоционального комфорта В ту или иную сторону и успешным процессом поиска работы, а также были определены факторы, влияющие на успешность процесса поиска работы психологическая и социальная поддержка.

Результаты исследования. Выявление психологических особенностей карьерного консультирования данной категории женщин, которые направлены на создание дифференцированных программ адаптации женщин после длительного перерыва в работе.

Ключевые слова: карьерное консультирование, психология труда, вторичная адаптация, эмоциональный комфорт, сопровождение трудоустройства.
B современном мире понятие карьеры значительно расширило свое определение, и, кроме профессиональной деятельности, охватывает все основные вехи жизненного пути человека, включая его самореализацию [20].

С учетом развития научно-технического прогресса и неоднократной смены государственно-экономического строя, изменилась и социальная роль женщины в современном обществе, и понятие карьеры женщины, кроме общепринятого социального статуса жены и домохозяйки, теперь рассматривается как один из факторов современного бизнес-сообщества. Очередная волна мирового экономического кризиса и одновременного демографического провала на рынке труда, как ни странно, значительно повысило значимость женщины, как работника, в оценке со стороны работодателей. Именно поэтому многие зарубежные компании используют программы поддержки и адаптации женщин после длительного перерыва в работе, например после декрета. 
В современной России точно так же набирают обороты госпрограммы поддержки женщин с детьми, однако они, в основном, направлены на возобновление профессиональных знаний, и практически не уделяется внимание тому, как реализует женщина эти знания, какие факторы оказывают влияние на ее дальнейшее трудоустройство и развитие карьеры.

Само понятие карьерное консультирование, как один из видов консалтинговых услуг, достаточно новое и многогранное для российского рынка понятие, которое содержит в себе элементы профориентации, маркетингового анализа и экспертной оценки по рынку труда, алгоритмов системного анализа, разработку стратегических планов и тактических действий, навыки использования психодиагностических методик и дальнейшего психологического сопровождения клиента.

Карьерное консультирование более конкретно в целеполагании, в отличие от психологического, и решает конкретные задачи, исходя из клиентского запроса, при этом, не смотря на взаимодействие с личностью и работой с его целями, мотивацией и оценкой действий, карьерное консультирование, в отличии от психологического консультирования, не ставит перед собой целью изменить саму личность но, несомненно, оказывает на нее влияние[8]. Карьерное консультирование достаточно персонифицировано, и одни и те же методы и техники могут быть неэффективными при определенной численности группы. Однако, существуют определенная система управления карьерой с набором инструментария, ко- торая и помогает индивиду построить свой карьерный путь.

В процессе работы в формате карьерной консультации, очень важно оценивать совокупность всех факторов, определяющих успешность построения карьеры, и выделить причинно-следственные связи успеха и неудач не только в карьере, но и в других взаимовлияющих сферах жизнедеятельности[8], особенно если карьерное консультирование касается женщин, находящихся в поиске работы после длительного перерыва. В рамках данного исследования попробуем выявить мотивационные факторы данной категории женщин, которые будут являться для них главными при выборе работодателя и условий работы, и соответственно, определить особенности успешного взаимодействия работодателя с данной категорией работников.

В исследовании принимали участие респонденты, из числа участниц Некоммерческого социального проекта «Женские истории», которые были выбраны по сходим биографическим, социально-географическим и профессиональным параметрам (место жительство-Москва, высшее образование, семейное положение- в разводе, не менее 3-х лет общий стаж работы, линейная категория должности в офисе, более 6 лет длительный перерыва в работе. Для оценки качественного и количественного анализа полученных данных, и их статистической обработки были использованы отечественные и зарубежные методики оценки и консультирования.

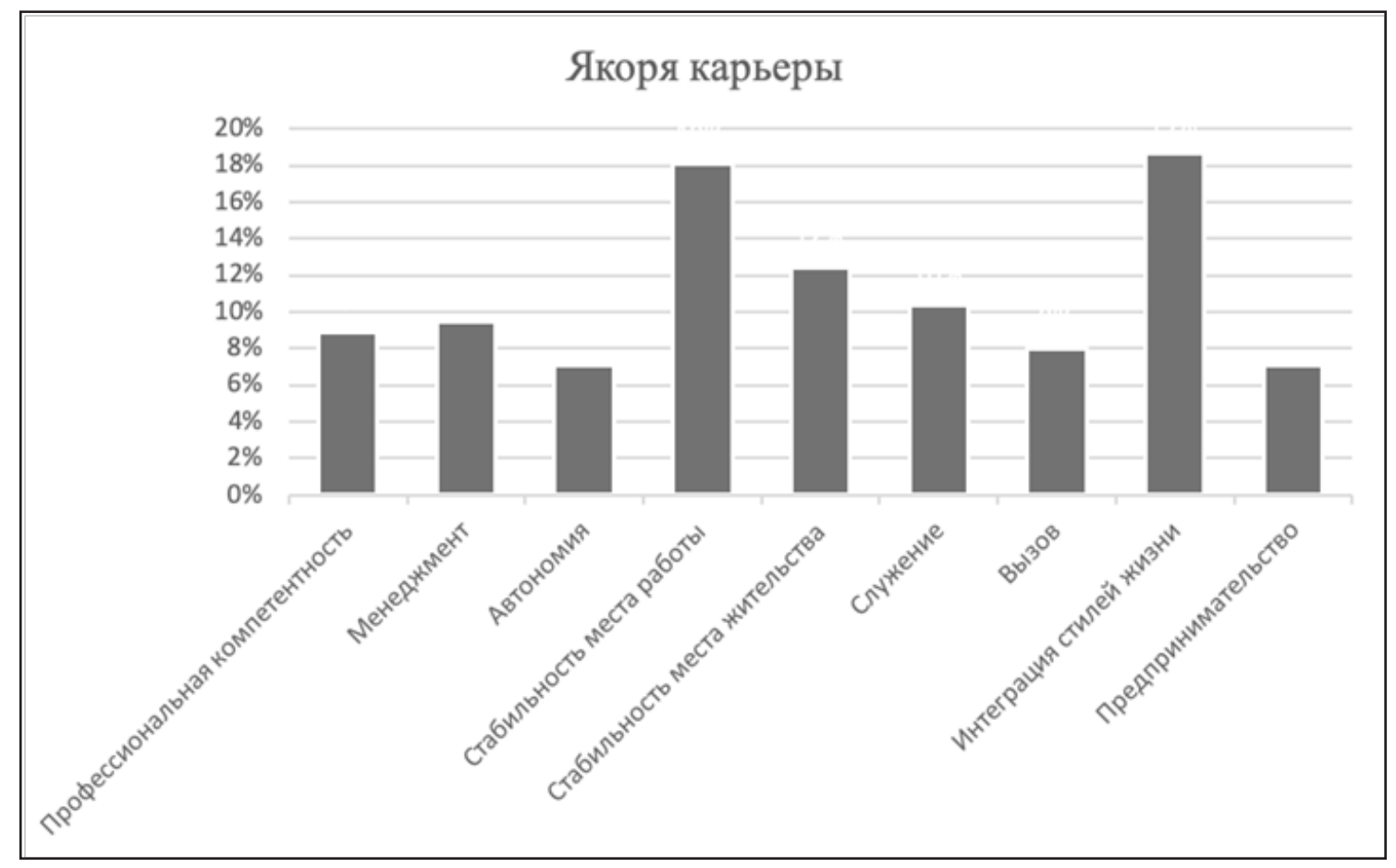

Рис. 1. Данные респондентов по опроснику Якоря карьеры Э. Шейна 
Оценивая полученные результаты испытуемых по опроснику «Якоря карьеры» Э. Шейна [17], мы видим, что в исследуемой группе большинство испытуемых выявили наибольшие значения в показателях «Интеграция стилей жизни» и «Стабильность места жительства», а наименьшие показатели - «Автономия» и «Вызов» (Рисунок №1).

При анализе данных результатов по опроснику Социально-психологической адаптации Даймонда-Роджерса, выявлены одинаковые значение минимума и максимума в Интегральном показателе «Эмоциональный комфорт», где показатель уровня минимального эмоционального комфорта и максимального эмоционального дискомфорта выявлен у 29\% респондентов по каждому показателю, что указывает на определенный эмоциональный дисбаланс, при котором 1/3 респондентов находится в состоянии наивысшего эмоционального подъема, срав- нимым с состоянием экзальтации, в то время как другая треть группы респондентов находится в состоянии эмоционального спада, сравнимым с депрессивным состоянием (Рисунок №2).

Такая нестабильности в оценке эмоционального комфорта респондентов, обусловлено текущей стрессовой ситуацией поиска работы после длительного перерыва в трудовой деятельности, и не смотря на высокий показатель Адаптации, Принятия себя и Принятия других, испытуемые находятся в новом для себя качестве- соискателей на рынке труда, и могут быть настроены как излишне оптимистично по отношению к текущей ситуации, так и излишне пессимистично.

Анализ опросника «Шкала удовлетворенности карьерой» Карпинский-Гижук [10] было необходимо в качестве подтверждения гипотезы о том, что положительная

\begin{tabular}{|l|c|c|c|}
\hline \multicolumn{1}{|c|}{ Показатель / \% респондентов } & $\begin{array}{c}\text { Высокое } \\
\text { значение }\end{array}$ & Норма & Низкое значение \\
\hline Интегральное значение Адаптация & $57 \%$ & $28 \%$ & $14 \%$ \\
\hline $\begin{array}{l}\text { Интегральное значение } \\
\text { Самопринятие }\end{array}$ & $43 \%$ & $43 \%$ & $14 \%$ \\
\hline $\begin{array}{l}\text { Интегральное значение Принятие } \\
\text { других }\end{array}$ & $43 \%$ & $57 \%$ & $0 \%$ \\
\hline $\begin{array}{l}\text { Интегральное значение } \\
\text { Эмоциональный комфорт }\end{array}$ & $43 \%$ & $14 \%$ & $43 \%$ \\
\hline $\begin{array}{l}\text { Интегральное значение } \\
\text { Интернальность }\end{array}$ & $57 \%$ & $43 \%$ & $0 \%$ \\
\hline $\begin{array}{l}\text { Интегральное значение Склонность } \\
\text { к доминированию }\end{array}$ & $29 \%$ & $43 \%$ & $29 \%$ \\
\hline Эскапизм (Уход от проблем) & $29 \%$ & $57 \%$ & $14 \%$ \\
\hline
\end{tabular}

Рис. 2. Данные респондентов по опроснику СПА Даймонда-Рождерса

\begin{tabular}{|c|c|c|c|c|c|}
\hline & $\begin{array}{c}\text { Я вполне } \\
\text { доволен(а) тем, } \\
\text { как } \\
\text { складывается } \\
\text { моя карьера }\end{array}$ & $\begin{array}{c}\text { Мне кажется, что я } \\
\text { пока еще не } \\
\text { сумел(а) достичь } \\
\text { профессионального } \\
\text { успеха }\end{array}$ & $\begin{array}{c}\text { В настоящее время } \\
\text { моя } \\
\text { профессиональная } \\
\text { жизнь близка к той, } \\
\text { о которой я } \\
\text { мечтал(а) }\end{array}$ & $\begin{array}{c}\text { В целом я } \\
\text { удовлетворен(а) } \\
\text { своими } \\
\text { достижениями в } \\
\text { профессии }\end{array}$ & $\begin{array}{c}\text { Если бы } \\
\text { представилась такая } \\
\text { возможность, я бы } \\
\text { совершенно по- } \\
\text { другому построил(а) } \\
\text { свою } \\
\text { профессиональную } \\
\text { карьеру }\end{array}$ \\
\hline $\begin{array}{c}\text { Среднее } \\
\text { значение баллов } \\
\text { по группе } \\
\text { респондентов }\end{array}$ & 11 & 11 & 11 & 12 & 12 \\
\hline
\end{tabular}

Рис. 3. Данные респондентов по опроснику «Шкала удовлетворенности карьерой» Карпинский-Гижук 
оценка прошлой карьеры влияет на степень эмоционального комфорта в изначально стрессовой ситуации поиска работы после длительного перерыва (Рисунок №3).

Фактор длительного перерыва в профессиональной деятельности оценивается испытуемыми как понижающий фактор будущих перспектив, что нашло отражение в результатах опроса на нижней границе среднего значения. Наименьшее количество баллов было по вопросам, связанных с вариантами реализации карьеры в будущем и невозможности изменения карьеры в прошлом. Так же прослеживается закономерность в удовлетворительной оценке прошедших событий в карьере как показателю личностного успеха, что вполне соотносится с высокими показателями «Самопринятие» и «Интернальность» из опросника СПА Роджерса-Даймонда.

Анализ результатов индивидуального карьерного консультирования [8] был завершающим этапом в текущем исследовании, и ставил перед собой несколько целей:

- Подтверждение данных по каждой испытуемой в виде оценки ее психоэмоционального состояния;

- Системную оценку психологических особенностей консультирования женщин после длительного перерыва в карьере.

В результате проведенных консультаций с помощью наблюдения, активного слушания и фиксации слов испытуемых, было выявлено косвенное подтверждение полученных данных по трем используемым методикам, а также определена психологическая особенность карьерного консультирования данной категории клиентов.

В ходе проведения консультаций 57\% испытуемых поделились своим страхом проявить профессиональную некомпетентность на работе и не оправдать ожиданиям работодателя, 71\% испытуемых заявили, что испытывают тревогу в связи с изменениями привычной жизни (график работы, расписание жизни семьи и привычного уклада)

Первичный «положительный импульс» со стороны психолога-консультанта, который направлен на поддержку- отмечают 94\% респондентов.

\section{Зак^ючение}

Факторы успеха и неудач в карьере женщин в большей степени зависят от степени эмоционального комфорта и положительной самомотивации, особенно в стрессовой ситуации поиска работы после длительного перерыва. В процессе исследования выявилась закономерность между дисбалансом эмоционального комфорта в ту или иную сторону и успешным процессом поиска работы. Те респонденты, которые показали высокие показатели (экзальтированный эмоциональный комфорт) терпели неудачи при поиске работы, так как не смогли оценить свои реальные возможности и соотношение текущих требований к своим компетенциям после длительного перерыва в трудовой деятельности, а также заранее строили планы по трудоустройству, что приводило к дальнейшему резкому эмоциональному спаду и эффекту «снежного кома».

Респонденты с низким уровнем эмоционального комфорта изначально находились в тревожном состоянии, с пессимистичным взглядом на перспективы своего трудоустройства после длительного перерыва, что настраивало их на неудачи, аккумулировало память и акцентировало внимание только на неудачных примерах.

В процессе проведения исследования, были определены факторы, влияющие на успешность процесса поиска работы женщин после длительного перерыва в профессиональной деятельности- психологическая и социальная поддержка,

В виду того, что после потери работы чаще всего теряются многие социальные и эмоциональные связи с коллегами, то человек невольно теряет связь и с рабочими процессами по своей деятельности, и с пониманием «внутренней кухни» своего сегмента рынка труда. Если же поиск работы растягивается на продолжительное время, особенно если кандидат выходит в поиск работы после длительного временного перерыва, то ситуация усугубляется состоянием тревожности и неуверенности в своих силах. Эти состояния достаточно легко определить по поведению кандидата: он занижает свои финансовые притязания, соглашается на первое попавшееся предложение, боится прохождение испытательного срока и нового поиска работы и т.п.

При создании проектов, включающих программы карьерного консультирования и сопровождения женщин после длительного перерыва в работе, необходимо разрабатывать дифференцированные и многоуровневые адаптационные программы как со стороны государства на федеральном уровне, так и со стороны организаций, на локальном уровне, которые будут направлены на психологическое сопровождение и открытую коммуникацию, так как от этих мер будет зависеть сбалансированное состояние эмоционального комфорта, и как следствие, быстрая адаптация для данной категории работников. 


\section{ЛИТЕРАТУРА}

1. Гижук Т.В. Психологические механизмы и закономерности саморегуляции профессиональной карьеры личности // Веснік ГрДУ імя Янкі Купалы. Сер. 3. 2014. № 1 (171). C. 156-161.

2. Гижук Т.В. Субъективная картина карьеры как психический образ: содержание, структура, функции // Веснік Брэсцкага універсітэта. Сер. 3. Філалогія. Педагогіка. Псіхалогія. 2015. № 1. С. 133-137.

3. Дикая Л.Г. Психическая саморегуляция функционального состояния человека (системно-деятельностный подход). М.: Изд-во «Институт психологии PAH», 2003.

4. Дубиненкова, Е.Н. Карьерное консультирование: метод. указания Яросл. гос. ун-т им. П. Г. Демидова. Ярославль: ЯрГУ,2010.,48 с.

5. Карпинский, К.В. Шкала удовлетворенности карьерой: разработка и психометрическая апробация/ К. В. Карпинский, Т. В. Гижук // Теоретическая и экспериментальная психология. - 2016. - Т. 9. - № 4. - С. 101-116.

6. Карпинский К.В. Психология профессиональной успешности: моногр. / К.В. Карпинский Т.В. Гижук.-Гродно:ГрГУ,2017. -169с.

7. Карпинский, К.В. Психическая регуляция карьеры и профес-сиональная успешность личности / К.В. Карпинский, Т.В. Гижук // Современные тенденции развития психологии труда и организационной психологии / отв. ред. Л.Г. Дикая, А.Л. Журавлев, А.Н. Занковский. - М.: Изд-во «Институт психологии PAH», 2015. - C. 478-490.

8. Карпинский К.В., Гижук Т.В. Субъективные критерии профессиональной успешности // Ананьевские чтения - 2014: Психологическое обеспечение профессиональной деятельности: материалы научной конференции, 21-23 октября 2014 г. / отв. ред. Г.С. Никифоров. СПб.: Скифия-принт, 2014. С. 11-13.

9. Кочунас Р. Психологическое консультирование: Учебное пособие для вузов- Москва: Академический проспект,2010.,222с.

10. Ломакина Т.Ю., Таппасханова М.А., Сергеева М.Г. Система поддержки карьеры различных категорий населения в контексте непрерывного развития личности: моногр.-Москва Издательский центр АНОО «ИЭТ», 2013.-228с.

11. Мальцева, Т.В. Психологическое консультирование личности в процессе профессионализации: учебное пособие / Т.В. Мальцева, И.Е. Реуцкая, В.Е. Петров. — Москва РИОР: ИНФРА-М, 2020. — (Высшее образование). — 136 с.

12. Мударисов А.А. Синягин Ю.В. Личностно-профессиональное развитие и карьера: траектории взаимовлияния- Москва:Издательство ИТРК, 2016.-192с.

13. Практикум по психологии профессиональной деятельности и менеджмента / под ред. Г.С. Никифорова, М.А. Дмитриева, В.М. Снеткова. — СПб., 2001.

14. Осницкий, А.К. Определение характеристик социальной адаптации / А.К. Осницкий // Психология и школа. — 2004. — №1.—C.43-56

15. Поваренков Ю.П. Проблемы психологии профессионального становления личности. Саратов: Саратовский государственный соци- ально-экономический университет, 2013.

16. Пряжников Н.С. Профессиональное и личностное самоопределение/ Н.С. Пряжников. —М.:МОДЭК,1996.-256с.

17. Пряжникова, Е.Ю. Психология труда: теория и практика: учебник для бакалавров Москва:Издательство Юрайт, $2016 ., 520$ c.

18. Толочек В.А. Современная психология труда. СПб.: Питер, 2005.

19. Толочек В.А. Профессиональная карьера как социально-психологический феномен.-М.:Изд-во «Институт психологии РАН»,2017.-262с.

20. Фетискин Н.П., Козлов В.В., Мануйлов Г.М. Социально-психологическая диагностика развития личности и малых групп. М., Изд-во Института Психотерапии, 2002. С.193-197.

21. Brown D. \& Brooks L. (1991). Career counseling techniques. Boston: Allyn \& Bacon.

22. Krumboltz J.D. (1994). Integrating career and personal counseling. Career Development Quarterly, 42, 143-148.

23. McGoldrick M. \& Gerson R. (1985). Genograms in family assessment. New York: Norton

24. Rogers, Carl R., and Rosalind F. Dymond, eds. Psychotherapy and Personality Change: Coordinated Research Studies in the Client-Centered Approach. Chicago: University of Chicago Press, 1954.

25. Roe A. \& Lunneborg R.W. (1991). Personality development and career choice. In D. Brown L. Brooks \& Associates (Eds.), Career choice and development: Applying contemporary theories topractice (2nd ed., pp. 68-101). San Francisco: Jossey-Bass.

26. Sampson J.R, Jr. \& Reardon R.C. (1990). Enhancing the design and use of computer-assisted career guidance systems. Alexandria, VA: American Counseling Association.

() Булаш Наталья Викторовна (natalya@bulash.ru). 